Article

\title{
Improving the Anti-Pilling Performance of Cellulose Fiber Blended Knitted Fabrics with 2,4,6-Trichloropyrimidine Treatment
}

\author{
Xue Dong, Tieling Xing $(\mathbb{D}$ and Guoqiang Chen * \\ National Engineering Laboratory for Modern Silk, College of Textile and Clothing Engineering, \\ Soochow University, Suzhou 215123, China; dongxue@suda.edu.cn (X.D.); xingtieling@suda.edu.cn (T.X.) \\ * Correspondence: chenguojiang@suda.edu.cn; Tel.: +86-512-6716-2166
}

Received: 12 September 2020; Accepted: 9 October 2020; Published: 12 October 2020

\begin{abstract}
Pilling is a common and unresolved problem in knitted fabrics, especially for the cellulose fiber blended fabrics, which not only causes an unattractive appearance and an uncomfortable handle, but also reduces the added value of the products. In this study, four different kinds of knitted fabrics were treated with 2,4,6-trichloropyrimidine (TLP) alkaline emulsion by dipping and pad-dry-cure modification processes. The surface morphology and chemical structure of original and treated fabrics were characterized by scanning electron microscopy (SEM), Fourier transform infrared spectroscopy (FTIR) and X-ray diffraction (XRD). The anti-pilling performance, thermal properties, physical and mechanical properties and color features of treated fabrics were also evaluated. The results indicated that TLP was successfully covalently crosslinked onto the surface of the cellulose fibers. The dipping process resulted in a better anti-pilling property than that of the pad-dry-cure process, and both treatments could bring about an excellent anti-pilling property and outstanding laundering durability. A pilling grade of 4.5 was achieved for the treated polyester/viscose $(T / V)$ fabric with the dipping process even after 20 washing cycles. In addition, the treated fabrics displayed an enhanced antistatic property and still maintained a soft handle. Besides, the bursting strength and air permeability of treated samples were found to have a slight deterioration, while no apparent differences were found in the color parameters and colorfastness of dyed fabrics. The above results demonstrate that 2,4,6-trichloropyrimidine has the potential application prospect in the functional finishing and home-caring of textiles.
\end{abstract}

Keywords: 2,4,6-trichloropyrimidine; anti-pilling; cellulose fiber blended fabrics; dipping process; pad-dry-cure process

\section{Introduction}

Cotton and viscose are important cellulose fibers, which are commonly used in the textile industry for producing high-grade fabrics and clothing due to their outstanding properties of a soft handle, good hydrophilicity, biodegradability, air permeability and skin-friendly [1-6]. However, pilling of knitted cellulose fibers products is an undesirable phenomenon during wearing and laundering that affects the handle and appearance and greatly shortens the service life of the products [7-10]. Pilling of knitted cellulose fabrics is a complex and dynamic process, in which the loose fibers separate from the yarn due to mechanical stresses such as rubbing, external pressure and fiber-fiber friction, and then intertwine with each other and appear on the surface of the fabric, resulting in pilling phenomenon [4,11-13]. In the blended fabric of cellulose and chemical fibers, the chemical fiber plays the role of an anchoring fiber because of its high strength, which makes the pilling of cellulose fibers less easy to fall off and aggravates the pilling period [14]. Therefore, reducing surface fuzzing and 
improving the inter-fiber friction coefficient and mobility of fibers in the yarn are the key factors to reduce fabric pilling [15].

At present, various chemical methods have been developed to solve the pilling problem, and the traditional resin finishing is still the main finishing method for fabrics [16-18]. Montazer et al. [19] applied various resins and crosslinking agents to reduce the pilling performance of viscose/polyester fabrics. Milind et al. [20] used various constructions of the fabric and three types of finishes to analyze the effect of resin finishes on the pilling behavior of knitted fabrics. Huang [9] used ultrafine copolyester granules to improve the pilling performance of polyester/cotton woven fabrics. Xu et al. [21] applied a modified polyurethane finishing agent for anti-pilling finishing. Tusief et al. [22] used a special anti-pilling finishing agent for anti-pilling treatment on dyed polyester/cotton blended fabrics. These chemical treatments can form a film on the surface of the fabric to reduce inter-fiber friction and improve the anti-pilling property. However, these methods have brought some problems such as the release of formaldehyde in resins, poor durability and a bad handle. What is more, some outfield induced methods have been developed to modify fabrics to achieve ecological sustainability [4]. For example, Kahandual [12] proved that cellulase could improve the pilling performance of bamboo fibers. Noreen [23] used aspergillus niger to improve the pilling resistance of polyester/cotton blended fabric. Zhu et al. [6] applied engineered water nanostructures (EWNS) to improve the anti-pilling property of knitted wool fabric. Rombaldoni et al. [15] used a hexamethyldimethicone (HMDSO)- $\mathrm{O}_{2}-\mathrm{Ar}$ gas mixture to form a film on wool knitted fabric through vapor deposition to achieve pilling prevention. Kan [24], Wan [11] and Mossotti et al. [25] applied plasma technology to the treatment of wool fabric and obtained good anti-pilling performance by etching and roughening the surface of wool fibers. Millington [26] and El-Sayed [27] used the ultraviolet (UV) method in the anti-pilling treatment of wool and cotton fabrics. Kowalczyk et al. [13] used gold/silver nanometer powder and adopted the sol-gel method to reduce the pilling performance of polyester/cotton blended fabric. Although these finishing methods have achieved good results, there are still some inherent shortcomings and limitations. The effect of the enzyme treatment technique is to eliminate pilling rather than to resist pilling, and the enzymes have high specificity and environmental requirements, which are also easy to lose activity. Plasma and engineered water nanostructures technologies require a large amount of energy and investment. UV radiation at different wavelengths can induce stronger or weaker effects on the cellulose fiber substrate, such as yellowing or pyrolysis [28]. The disadvantage of the sol-gel method is that the higher the content of the mixed low-melting fiber, the higher the cost, and the worse the handle. Furthermore, these methods are not effective enough for mass production and some of them may not be applicable to cellulose fiber blended knitted fabrics.

Pyrimidines are important substances in life activities and have attracted much attention due to their strong biological activity [29]. 2,4,6-trichloropyrimidine is a heterocyclic compound containing a pyrimidine ring, which is a very important pharmaceutical and reactive dye intermediate. It is mainly used in the synthesis of anti-microbial infective drugs, hypnotic and sedative drugs and reactive dye. However, little work has been reported on its application in textile functional modification and as a chemical crosslinking agent.

In this study, the alkaline 2,4,6-trichloropyrimidine emulsion system was first applied to solve the fuzzing and pilling problem of cellulose fiber blended knitted fabrics. Cotton, cotton/viscose, polyester/cotton and polyester/viscose were treated in a highly stable emulsion by dipping and pad-dry-cure finishing processes. A modified Martindale method and a new evaluation method were used to evaluate the pilling performance of untreated and treated samples. The Pill Grade 3D Fabric Scan \& Grade System was chosen to objectively evaluate the pill density, pill count, fuzz loft and pilling grade. The influence of TLP concentration on anti-pilling performance was investigated. The thermal properties, washing durability, physical and mechanical properties and color change of the treated and untreated fabrics were also measured. 


\section{Materials and Methods}

\subsection{Materials}

Knitted fabrics were provided by Suzhou Yunzhi Textile Co., Ltd. (Suzhou, China), and the specification parameters are shown in Table 1. The fabrics were boiled in liquid soap for $30 \mathrm{~min}$ before use. 2,4,6-trichloropyrimidine (TLP) was bought from Shanghai Adama Reagent co., Ltd. (Shanghai, China). $\mathrm{Na}_{2} \mathrm{CO}_{3}, \mathrm{NaCl}$, span 20 and tween 80 were purchased from Shanghai Aladdin Biochemical Technology Co., Ltd. (Shanghai, China). Non-foam powder was bought from Shenggong Biological Engineering Co., Ltd. (Shanghai, China).

Table 1. The specification parameters of knitted fabrics.

\begin{tabular}{ccccc}
\hline Knitted Fabrics & $\begin{array}{c}\text { Component } \\
\mathbf{( \% )}\end{array}$ & $\begin{array}{c}\text { Horizontal and Vertical Density } \\
\text { (circle/5 } \mathbf{~ c m})\end{array}$ & $\begin{array}{c}\text { Thickness } \\
\mathbf{( m m})\end{array}$ & $\begin{array}{c}\text { Surface Density } \\
\left(\mathbf{g} / \mathbf{m}^{\mathbf{2}}\right)\end{array}$ \\
\hline Cotton (C, undyed) & 100 & $70 \times 85$ & 0.65 & 191.3 \\
Cotton/viscose (C/V, dyed) & $60 / 40$ & $80 \times 110$ & 0.62 & 148.4 \\
Polyester/cotton (T/C, undyed) & $65 / 35$ & $85 \times 95$ & 0.57 & 182.2 \\
Polyester/viscose (T/V, dyed) & $62 / 38$ & $80 \times 140$ & 0.71 & 184.3 \\
\hline
\end{tabular}

\subsection{Preparation of TLP Dispersed Emulsions}

Stable and durable dispersed emulsions of 2,4,6-trichloropyrimidine (TLP) were prepared as follows: span 20 (20\% o.w.t) and tween 80 (30\% o.w.t) were added into an appropriate amount of water and then emulsified at a speed of 10,000 rpm for $30 \mathrm{~min}$. In the emulsification process, TLP was gradually added into the solution in stages. Finally, $\mathrm{Na}_{2} \mathrm{CO}_{3}, \mathrm{NaCl}$ and non-foam powder were added into the emulsion and stirred evenly to obtain the final alkaline emulsion system with uniform dispersion.

\subsection{Preparation of Anti-Pilling Knitted Fabrics}

For the dipping process, fabrics were dipped into the dispersion emulsion at a concentration of $6-24 \%$ in an oscillating dyeing machine. The liquor ratio of the fabric and the dispersion emulsion of TLP was 1:30. A temperature rise was carried out from 30 to $95{ }^{\circ} \mathrm{C}$ at a heating rate of $1-2{ }^{\circ} \mathrm{C} / \mathrm{min}$, and incubation circulation was carried out for $45 \mathrm{~min}$ at $95^{\circ} \mathrm{C}$. For the pad-dry-cure process, firstly, fabrics with a size of $15 \mathrm{~cm} \times 15 \mathrm{~cm}$ were immersed in liquid suspensions with TLP (20-80 g/L), $\mathrm{NaCl}(40 \mathrm{~g} / \mathrm{L}), \mathrm{Na}_{2} \mathrm{CO}_{3}(20 \mathrm{~g} / \mathrm{L})$ and foam-free powder $(2 \mathrm{~g} / \mathrm{L})$ for $15 \mathrm{~min}$, and then the samples were removed and passed through a padder. After two paddings, the samples were dried at $80{ }^{\circ} \mathrm{C}$ for 3 min and cured at $150^{\circ} \mathrm{C}$ for $3 \mathrm{~min}$. At last, the treated fabrics were subsequently washed with deionized water at $60^{\circ} \mathrm{C}$ for $15 \mathrm{~min}$ and then thoroughly rinsed with cold water. The samples were dried and conditioned at $20 \pm 1{ }^{\circ} \mathrm{C}$ and $\mathrm{RH} 65 \pm 5 \%$ for $24 \mathrm{~h}$ before any characterization. In the Result and Discussion section, C-1, C/V-1, T/C-1 and T/V-1 and C-2, C/V-2, T/C-2 and T/V-2 samples denote the fabrics treated with dipping and pad-dry-cure processes, respectively.

\subsection{Characterization and Measurements}

\subsubsection{Pilling Characterization}

The pilling property of fabric samples was measured according to ISO 12945-2: 2000 (modified Martindale method) with the trajectory of Lissajous, Figure 1a. The samples were cut into $150 \mathrm{~mm} \times 150 \mathrm{~mm}$ pieces and rubbed on the Martindale fuzzing-pilling and abrasion meter (MESDAN-LAB, Mesdan Ltd., Peugnago del (BS), Italy) for 2000 rubs. The pill density, pill count, fuzz loft and pilling grade were quantified by the Pill Grade 3D Fabric Scan \& Grade System (SDL Atlas Ltd., Chicago, IL, USA). Figure 1b shows the fabric specimen rolling over the drive rod while the video camera captures the video images. After scanning the whole specimen, the Pill Grade analyzes each horizontal image to detect and measure the pills, then plots the XY position of each pill on the displayed graph with semicircle marks, as shown 
in Figure 1c. The pilling standard used for evaluating the fabrics had the following scales: 5: no change; 4: slight surface fuzzing and/or partially formed pills; 3: moderate surface fuzzing and/or moderate pilling; 2: distinct surface fuzzing and/or distinct pilling; 1: dense surface fuzzing and/or severe pilling. Four repetitions were performed for each specimen.

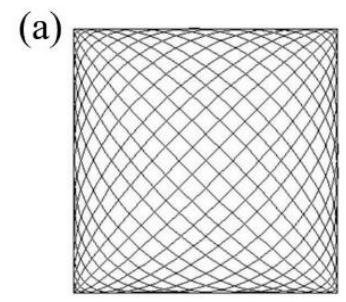

The trajectory of Lissajous

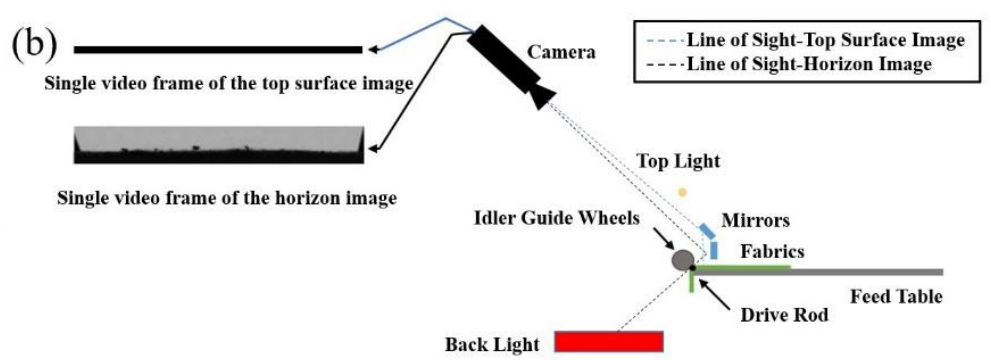

(c)

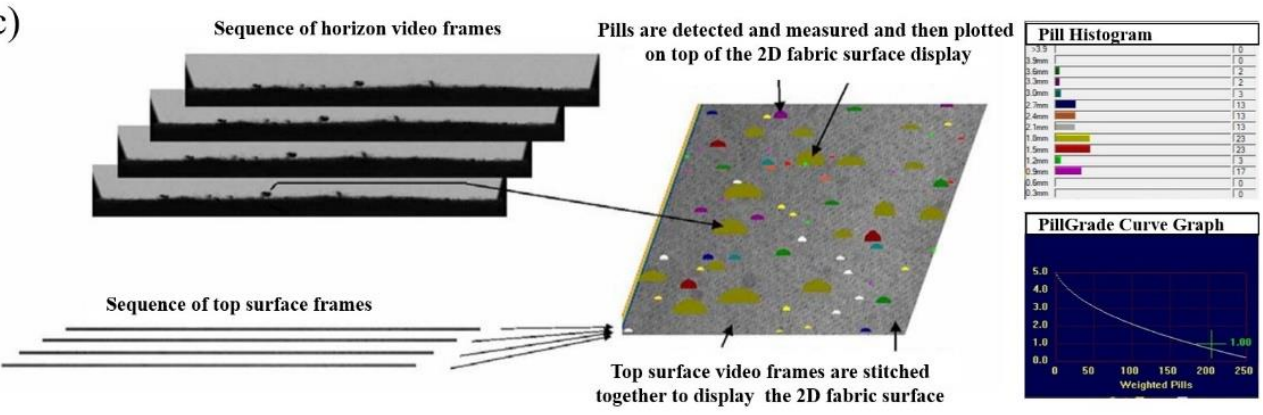

Figure 1. Test and evaluation of pilling performance. (a) the trajectory of Lissajous; (b) the process of rolling over fabric samples and capturing sample images in a video recorder; (c) the graph using semicircular markers color-coded by pill size.

\subsubsection{Surface Morphology and Structure Analysis}

The surface morphologies of untreated fabrics, TLP-treated knitted fabrics and their respective samples after the pilling test were carried out with a tabletop scanning electron microscope (Hitachi TM 3030, Tokyo, Japan) and the scanning electron microscope was controlled at $15 \mathrm{kV}$. An energy disperse spectroscopy (EDS) spectrometer fitted to TM3030 SEM was applied for elemental analysis. The photographs of the pilling morphology were captured by digital camera (Olympus Imaging Corp., Tokyo, Japan). The FTIR spectra of fabric samples were recorded by a Nicolet 5700 FTIR instrument (Thermo Fisher Scientific Inc., New York, NY, USA) using KBr pellets. The XRD powder patterns were acquired by using a Philips $X^{\prime}$ pert-pro MRD.

\subsubsection{Thermal Stability and Washing Resistance}

The thermogravimetric (TG) analysis was conducted on the PerkinElmer Diamond TG-DTA thermal analyzer (PerkinElmer, Waltham, MA, USA) under an air atmosphere with a gas flow rate of $20 \mathrm{~mL} / \mathrm{min}$. The heating temperature range from 40 to $700{ }^{\circ} \mathrm{C}$ at a heating rate of $10^{\circ} \mathrm{C} / \mathrm{min}$ [30]. The washing resistance of the anti-pilling performance was evaluated by repeated washing according to the standard AATCC61-2006 method in the Wash Tec-P Fastness Tester (Roaches International, Kent, UK). Each washing was carried out at $40{ }^{\circ} \mathrm{C}$ for 10 min containing $2 \mathrm{~g} / \mathrm{L}$ commercial detergent.

\subsubsection{Physical and Mechanical Properties}

The bursting strength of the fabrics was investigated by an Instron 3365 Universal Testing Machine (Instron, Boston, MA, USA) according to GB/T 19976-2005. The extension speed was $300 \mathrm{~mm} / \mathrm{min}$ and the diameter of the steel ball was $38 \mathrm{~mm}$. The surface friction and bending properties were measured by the Kawabata Evaluation System for Fabric (Kato Tech Co. Ltd., Kyoto, Japan). The air permeability was tested by a M021A air permeability tester (SDLATLAS, Shenzhen, China) according 
to ISO 9237:1995 at a pressure of $200 \mathrm{~Pa}$. Five different tests were carried out for each fabric sample. The antistatic property was tested by a H0110 V2 electrostatic attenuation tester (Daiei, Tokyo, Japan) according to GB/T 12703.1-2008. All samples $(45 \mathrm{~mm} \times 45 \mathrm{~mm}$ ) must be dehumidified in an electronic dry cabinet under the condition of temperature $20 \pm 2{ }^{\circ} \mathrm{C}$ and RH $35 \pm 5 \%$ for $24 \mathrm{~h}$ before testing.

\subsubsection{Color Change Performance}

The color parameters of the untreated and treated fabrics were investigated by the $\mathrm{L}$ (whiteness/darkness), a (redness/greenness) and b (yellowness/blueness) values using a Hunter Lab Ultra Scan PRO reflectance spectrophotometer with illuminant D65 and $10^{\circ}$ standard observer [31]. The whiteness index (WI) was calculated using the following equation:

$$
\mathrm{WI}=100-\left[(100-\mathrm{L})^{2}+\mathrm{a}^{2}+\mathrm{b}^{2}\right]^{1 / 2}
$$

The colorfastness of rubbing and washing was determined according to ISO 105-X16 and ISO 105-C10.

\section{Results and Discussion}

\subsection{Influence of TLP Concentration on Anti-Pilling Performance with Dipping and Pad-Dry-Cure Processes}

TLP concentration was discussed to evaluate the influence on anti-pilling performance and crosslinking effect of cellulose fibers. As shown in Figure 2, a higher pilling grade and less pills were obtained by increasing the TLP concentration in the dipping finishing process. However, when the concentration increased to $30 \%$, the pilling grade remained the same and even decreased a little. Similarly, as shown in Figure 3, with the increase in the TLP concentration before $80 \mathrm{~g} / \mathrm{L}$, the pilling grade of the pad-dry-cure process-treated fabrics increased continuously. In conclusion, TLP concentrations of $24 \%$ and $80 \mathrm{~g} / \mathrm{L}$ were appropriate for the dipping and pad-dry-cure finishing processes.
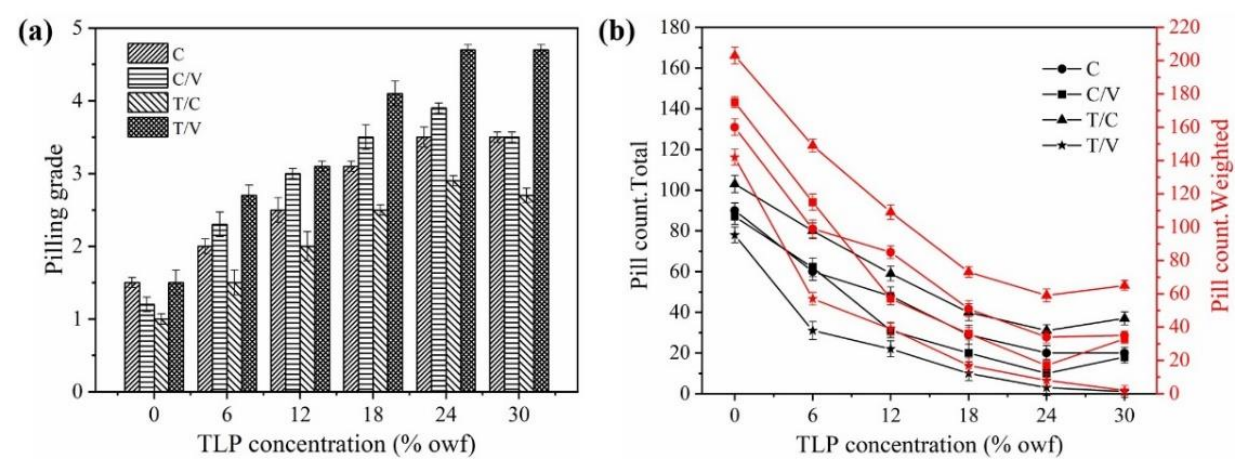

Figure 2. Pilling grade (a) and pill count (b) of fabrics treated with the dipping process at various TLP concentrations.
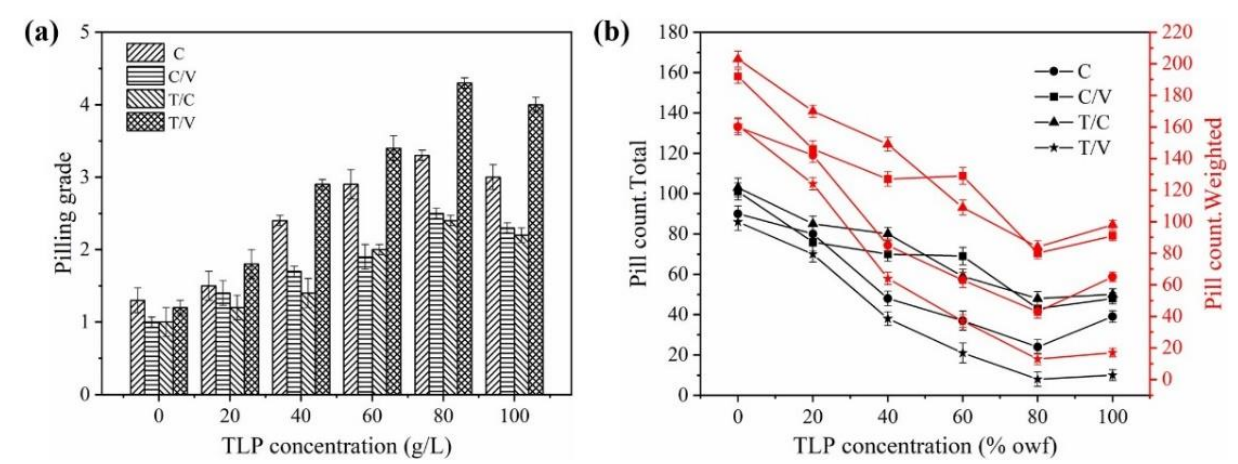

Figure 3. Pilling grade (a) and pill count (b) of fabrics treated with the pad-dry-cure process at various TLP concentrations. 


\subsection{Anti-Pilling Performance}

The digital camera images of original and treated fabric samples after 2000 pilling cycles and the original samples are shown in Figure 4. Obviously, after 2000 rubs, the control samples (original samples after pilling) showed the most severe pilling with pills covering a large proportion of the specimen surface, while all four kinds of cellulose-treated samples appeared to have excellent anti-pilling performance. For example, the surface of the $\mathrm{T} / \mathrm{V}$ fabric treated with the dipping process is smooth and flat, without any pills, which is close to the original samples.

(a)
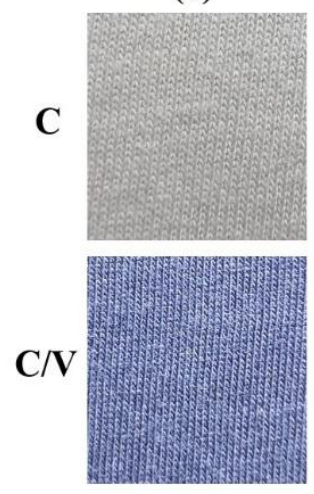

$\mathbf{T} / \mathbf{C}$

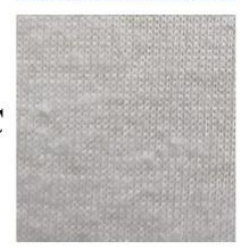

$\mathbf{T} / \mathbf{V}$

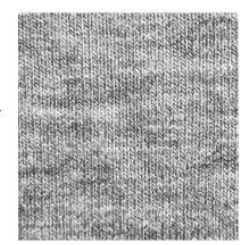

(b)
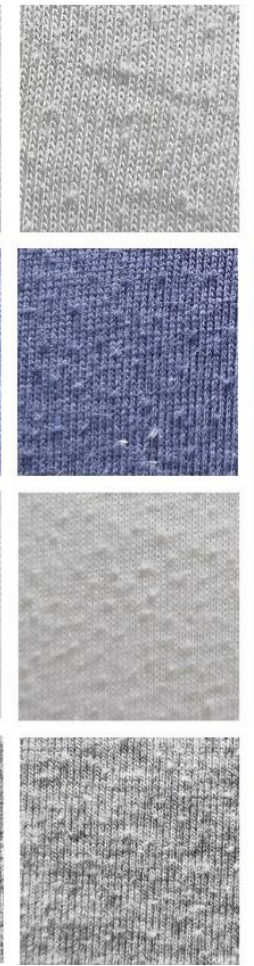

(c)
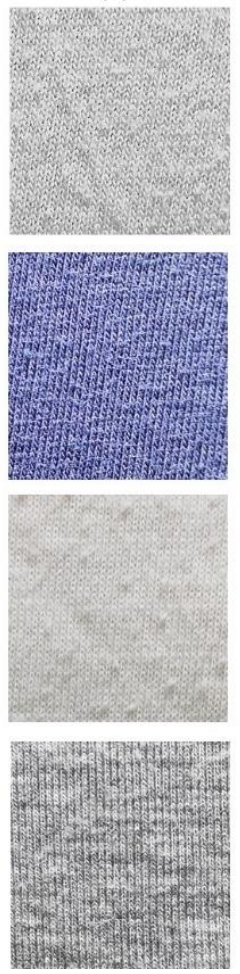

(d)
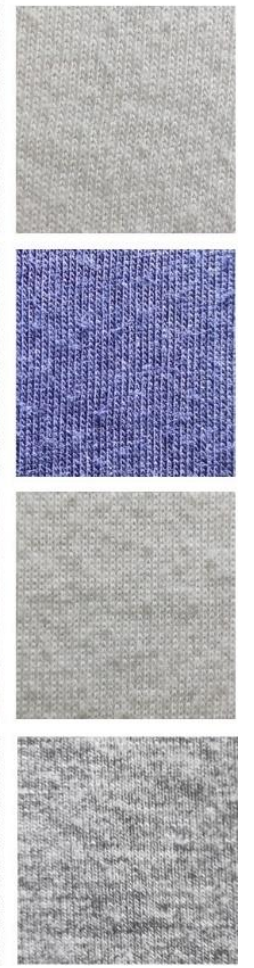

Figure 4. Digital camera images of original samples and pilling samples after 2000 rubs. (a) Original samples; (b) control samples; (c) treated with the dipping process; (d) treated with the pad-dry-cure process.

Pilling formation takes place by fibers working out of the yarn to form freestanding fuzz, in which the fibers or other fibers become entangled. Pills are fiber balls or clumps located on the top of the fabric, and the straight down 2D imaging of the sample is insufficient to measure pills because the pill height is a critical factor in determining the degree of pilling. Therefore, the pill size and volume distribution, pill density (total number of pills in the inspection area/total size of the inspection area), pill count (total number of pills in the inspection area), average pill height-compensated diameter (avg pill HC diam) and fuzz loft (the height of the dense layer of fabric fuzz) are also important parameters to represent the pilling performance of the fabric. As shown in Figure 5 and Table 2, all treated samples that involved two finishing processes obtained improvement of at least 1.4 grade compared with untreated samples. In addition, there is good correlation between pilling grade and the pill parameters. The higher the pilling grade, the lower the pill density and pill count of the fabric. For example, the $\mathrm{T} / \mathrm{V}$ fabric treated with the dipping process had an increased pilling grade of 4.7 and decreased pill count, and the number of pills on the fabric surface is only 2 in the $5 \mathrm{~cm} \times 5 \mathrm{~cm}$ sampling area. It can be clearly demonstrated that TLP treatment greatly slowed down the formation of pilling. 
(a)

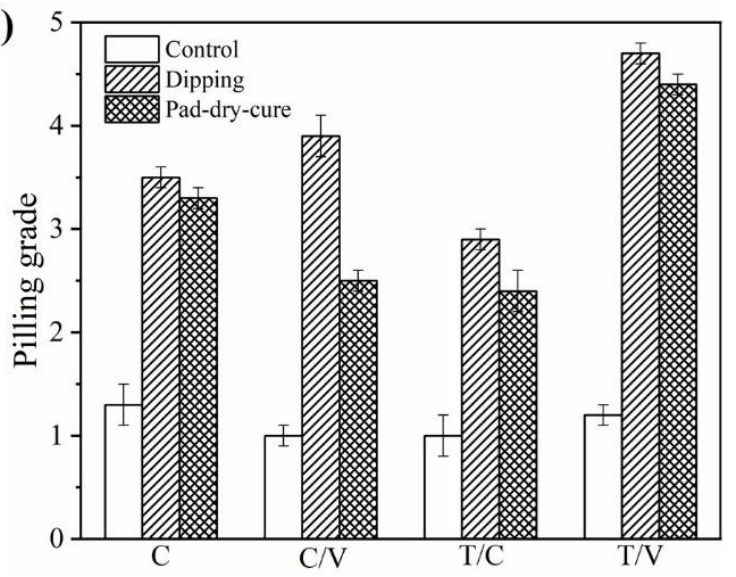

(b)

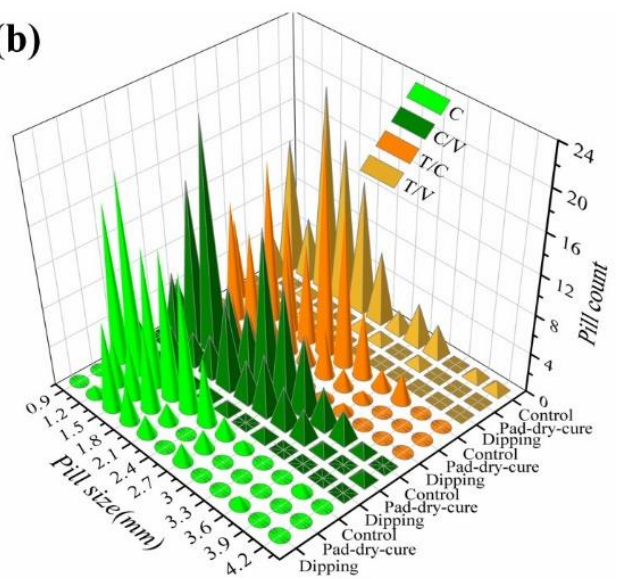

Figure 5. Pilling grade (a), pill size and volume distribution (b) of original and treated fabrics after 2000 rubs.

Table 2. Pill density, pill count, average pill height-compensated diameter (avg pill HC diam), fuzz loft and average pilling grade of original and treated fabrics after 2000 rubs.

\begin{tabular}{|c|c|c|c|c|c|c|c|c|}
\hline \multirow{2}{*}{ Sample } & \multirow{2}{*}{$\begin{array}{l}\text { Pill Density } \\
\left(\mathrm{cm}^{2} / \text { inch }^{2}\right)\end{array}$} & \multirow{2}{*}{$\begin{array}{l}\text { Weighted Pill Density } \\
\qquad\left(\mathrm{cm}^{2} / \text { inch }^{2}\right)\end{array}$} & \multicolumn{2}{|c|}{ Pill Count } & \multirow{2}{*}{\multicolumn{2}{|c|}{$\begin{array}{l}\text { Avg Pill HC Diam } \\
\text { (mm/in) }\end{array}$}} & \multirow{2}{*}{ Fuzz Loft } & \multirow{2}{*}{$\begin{array}{l}\text { Avg Pilling } \\
\text { Grade }\end{array}$} \\
\hline & & & Total & Weighted & & & & \\
\hline $\mathrm{C}-0$ & $3.6 / 23.1$ & $6.4 / 41.0$ & 90 & 160 & 1.12 & 0.044 & 2.75 & 1.3 \\
\hline$C-1$ & $0.8 / 5.1$ & $1.4 / 8.7$ & 20 & 34 & 1.07 & 0.042 & 1.44 & 3.5 \\
\hline$C-2$ & $1.0 / 6.1$ & $1.7 / 11.0$ & 24 & 43 & 1.09 & 0.043 & 1.56 & 3.3 \\
\hline $\mathrm{C} / \mathrm{V}-0$ & $4.0 / 25.9$ & $7.6 / 49.2$ & 101 & 192 & 1.42 & 0.056 & 2.08 & 1.0 \\
\hline $\mathrm{C} / \mathrm{V}-1$ & $0.5 / 3.1$ & $0.8 / 5.4$ & 12 & 21 & 1.07 & 0.042 & 1.26 & 3.9 \\
\hline $\mathrm{C} / \mathrm{V}-2$ & $1.8 / 11.5$ & $3.1 / 20.0$ & 45 & 78 & 1.1 & 0.043 & 1.71 & 2.5 \\
\hline $\mathrm{T} / \mathrm{C}-0$ & $4.1 / 26.4$ & $8.1 / 52.0$ & 103 & 203 & 1.49 & 0.059 & 2.97 & 1.0 \\
\hline $\mathrm{T} / \mathrm{C}-1$ & $1.2 / 7.9$ & 2.3/15.1 & 31 & 59 & 1.28 & 0.051 & 2.20 & 2.9 \\
\hline $\mathrm{T} / \mathrm{C}-2$ & $1.9 / 12.0$ & $3.4 / 22.0$ & 47 & 86 & 1.30 & 0.051 & 2.19 & 2.4 \\
\hline $\mathrm{T} / \mathrm{V}-0$ & $3.4 / 22.0$ & $6.4 / 41.2$ & 86 & 161 & 1.24 & 0.049 & 1.72 & 1.2 \\
\hline $\mathrm{T} / \mathrm{V}-1$ & $0.1 / 0.5$ & $0.2 / 1.0$ & 2 & 4 & 1.02 & 0.040 & 1.27 & 4.7 \\
\hline $\mathrm{T} / \mathrm{V}-2$ & $0.3 / 2.0$ & $0.5 / 3.3$ & 8 & 13 & 1.15 & 0.045 & 1.44 & 4.4 \\
\hline
\end{tabular}

However, different finishing methods have different effects on the same fabric. Figure 5a shows that the pilling grades of four knitted fabrics treated by the dipping process are all higher than those of the pad-dry-cure process. It can be concluded that compared with the pad-dry-cure process, more TLP penetrates into the yarns and forms a crosslink with the fibers in the dipping process. Furthermore, the effect of the same finishing process on different kinds of knitted fabrics differs greatly. The pilling grades of the treated fabrics are in the following order: $\mathrm{T} / \mathrm{V}>\mathrm{C} / \mathrm{V}>\mathrm{C}>\mathrm{T} / \mathrm{C}$. This is because pilling of textile fabrics is an extremely complex process that is affected by many factors.

Washing causes the fabric to be denser, where the yarns are closer to each other, and more fibers protrude per unit area, hence increasing pilling. Household washing durability is an important property of functional modified textiles. Figure 6 shows the pilling grades of four kinds fabrics treated with two different finishing processes before and after 10 and 20 washing cycles. After 10 washing cycles, the pilling grade of all treated fabrics decreased within 0.5 grades, except for $C$ and $C / V$ fabrics treated with the dipping process. Moreover, after 20 washing cycles, there was no substantial change in all of the treated fabrics. The fabrics prepared by the two different modification processes exhibited satisfactory durability of anti-pilling performance. The underlying reason may be because of the electrostatic attraction between TLP and cellulosic molecules, and the hydroxyl groups in cellulose molecules are crosslinked with C-Cl in TLP, which eventually enhance the durability of TLP-treated fabrics. 


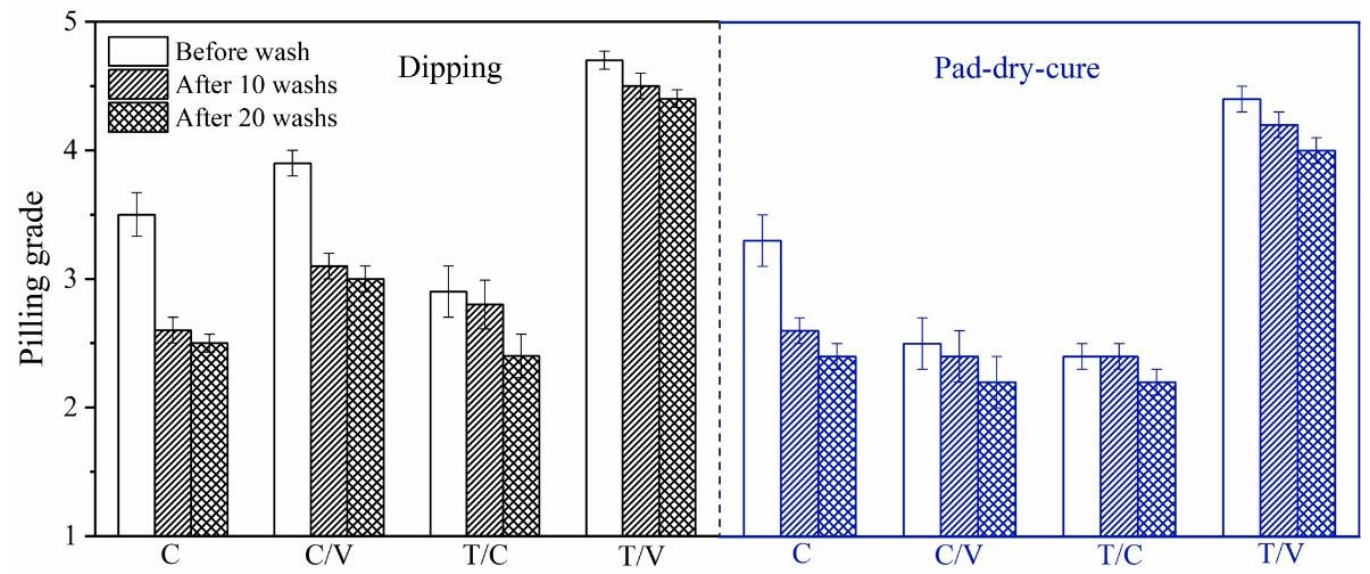

Figure 6. Pilling grade of treated fabrics before and after 10 and 20 washing cycles.

\subsection{SEM-EDS Analysis}

The SEM images of original and TLP-treated fabrics with two different finishing processes were captured by TM3030 SEM at 3000 magnification. The original cotton fibers present a typical convoluted and wrinkle-like structure because of the longitudinal fibril structure [32]. As shown in Figure 7, it can be clearly observed that the cotton fiber surface is covered with a layer of dense film, smoothing the partially damaged fibers on the surface of the fabric, which would increase the roughness of cotton fibers. The SEM image shows the original viscose fibers in $\mathrm{C} / \mathrm{V}$ and $\mathrm{T} / \mathrm{V}$ fabrics with a typical toothed profile and clear grooves. It is illustrated that after dipping and pad-dry-cure treatments with TLP, many particles are found on the surface of the viscose fibers, and these particles join to form a thin film, making the grooves on the viscose fiber shallower. However, the surface of polyester fibers in $\mathrm{T} / \mathrm{C}$ and $\mathrm{T} / \mathrm{V}$ fabrics are smooth and flat, almost unchanged before and after treatment, indicating that TLP did not form crosslinking with the polyester fibers.
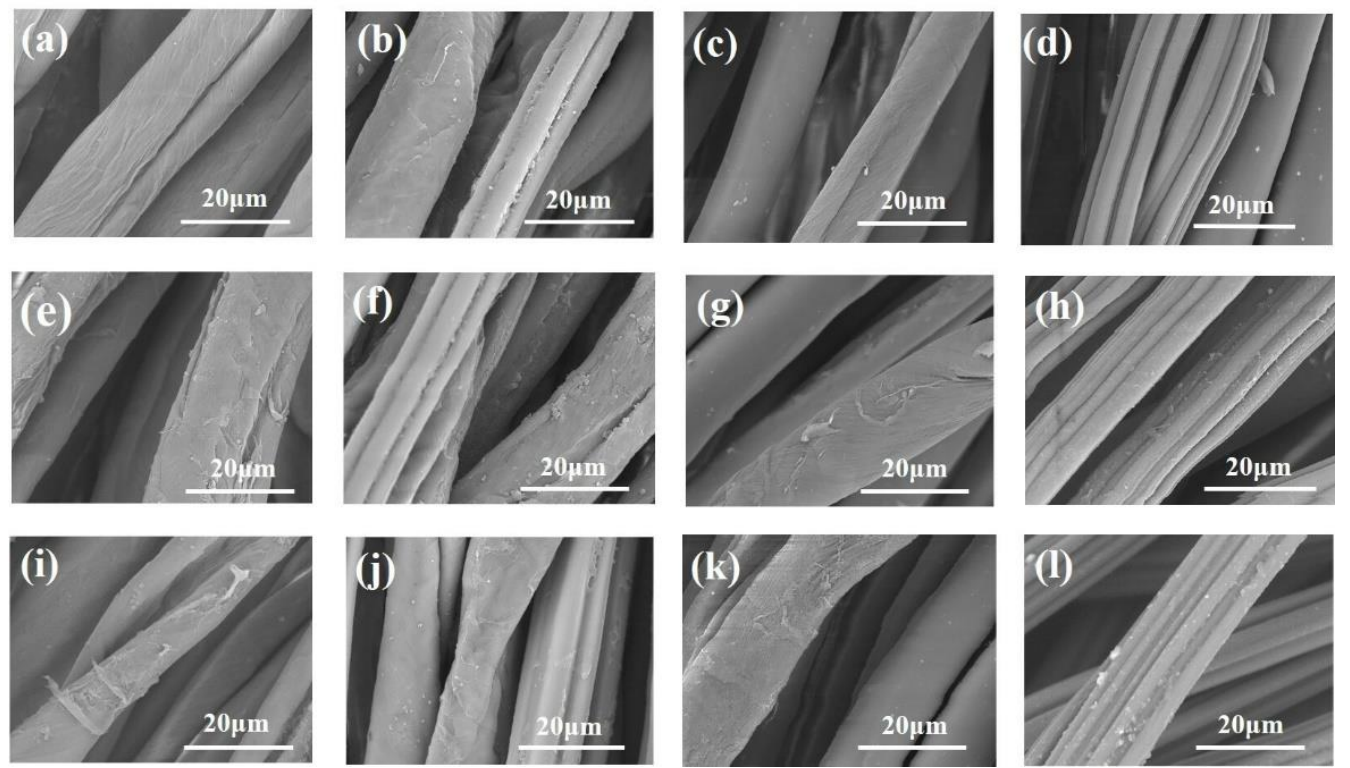

Figure 7. SEM images of original and treated fabrics. (a-d) original $C, C / V, T / C$ and $T / V$ fabrics; $(\mathbf{e}-\mathbf{h})$ treated $\mathrm{C}, \mathrm{C} / \mathrm{V}, \mathrm{T} / \mathrm{C}$ and T/V fabrics with the dipping process; (i-l) treated C, C/V, T/C and T/V fabrics with the pad-dry-cure process.

In addition, the EDS spectrum was used to determine the elements of the cotton fiber and viscose fiber in the polyester/viscose fabric. As shown in Figure 8, all the elements $(\mathrm{C}, \mathrm{O}$ and $\mathrm{Cl})$ were finely 
dispersed on the treated cotton and viscose fibers. The $\mathrm{Cl}$ content of cotton fiber treated with dipping and pad-dry-cure processes were $4.915 \%$ and $2.920 \%$, respectively, and the $\mathrm{Cl}$ content of viscose fiber in the treated polyester/viscose fabric was $5.496 \%$ and $3.509 \%$, respectively. The above results indicate that TLP mainly adheres on the surface of fibers and crosslinks with cotton and viscose fibers.
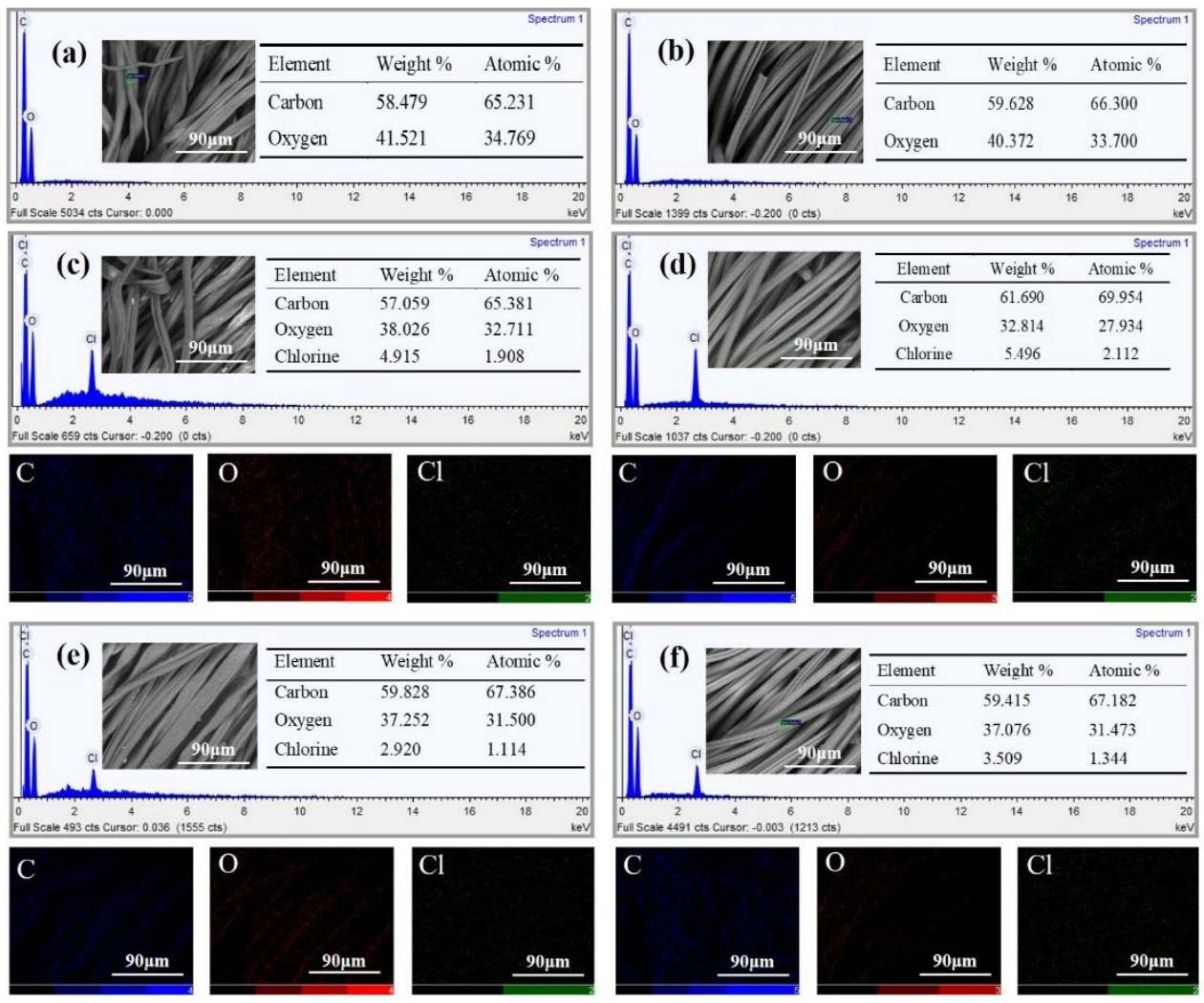

Figure 8. EDS spectra of original and treated fibers. $(\mathbf{a}, \mathbf{b})$ original cotton and viscose fibers; $(\mathbf{c}, \mathbf{d})$ treated cotton and viscose fibers with the dipping process; $(\mathbf{e}, \mathbf{f})$ treated cotton and viscose fibers with the pad-dry-cure process.

To further characterize the changes in surface morphology and polymerized binding strength as a result of the pilling test, SEM was used to image the treated fabrics before and after pilling tests. Figure 9 shows the fuzzing and pilling appearance of fabric samples before and after 2000 cycles of rubbing at 100 magnification. Compared with the original samples (Figure 9a), there were apparent differences in surface fuzzing and pilling for the treated samples, as shown in Figure 9c. The surface of treated fabrics was clear and almost without any fuzzing before and after 2000 cycles of rubbing, especially for $\mathrm{C} / \mathrm{V}$ and T/V (Figure 9c), which correlates well with Figure 4c. This was probably due to that the dipping finishing process increased the surface roughness and friction, which consequently restricted the fiber movements, thus reducing the pilling tendency [33]. Moreover, the crosslinking between $\mathrm{C}-\mathrm{Cl}$ bond of TLP polymer and $-\mathrm{OH}$ of cellulose fibers could restrict the migration of inner fibers to the surface of fabrics. 
(a)
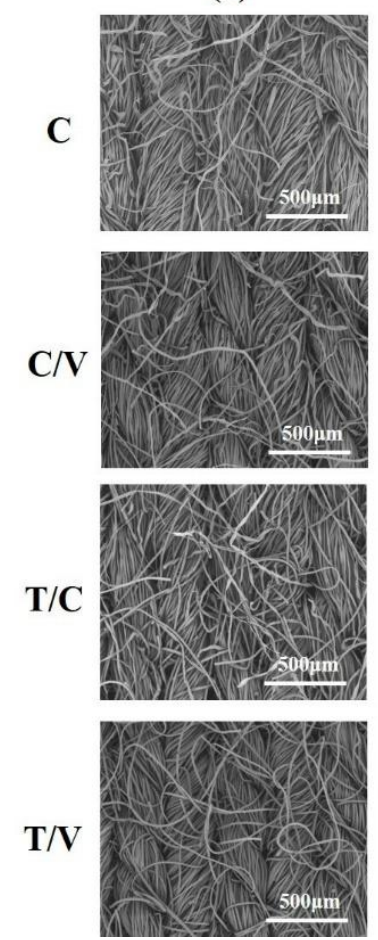

(b)
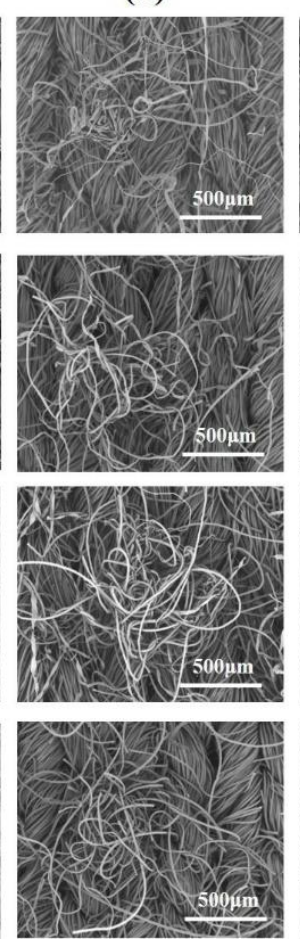

(c)
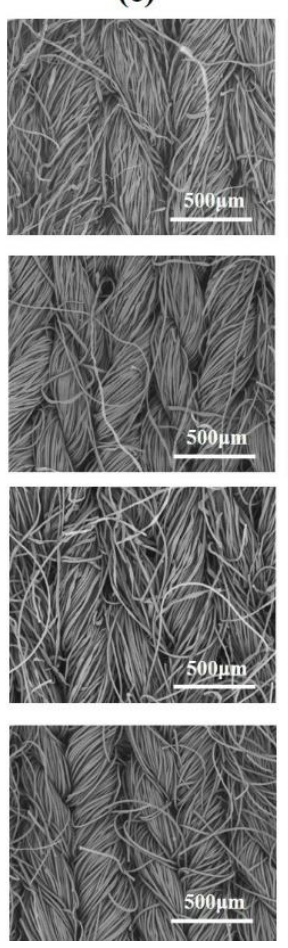

(d)
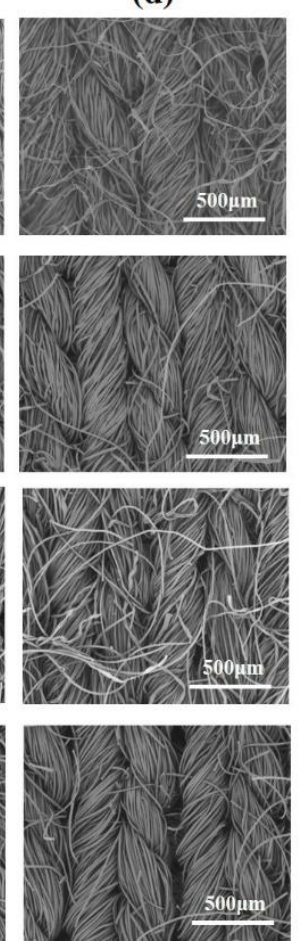

Figure 9. SEM images of original and treated fabrics before and after 2000 pilling cycles. (a) original fabrics; (b) original fabrics after pilling; (c) treated fabrics with the dipping process; (d) treated fabrics with the dipping process after pilling.

\subsection{FT-IR Analysis}

FTIR spectra of original and treated fabrics are reported in Figure 10. As shown in Figure 10a,b, the characteristic absorption peaks of cellulose fibers at around 3347, 2900, 1160 and $1060 \mathrm{~cm}^{-1}$ were, respectively, assigned to the stretching vibrations of $\mathrm{O}-\mathrm{H}, \mathrm{C}-\mathrm{H}, \mathrm{C}-\mathrm{C}$ and $\mathrm{C}-\mathrm{O}$ bonds, and a characteristic absorption peak near $1640 \mathrm{~cm}^{-1}$ is the $\mathrm{OH}$ of water absorbed from cellulose [34-36]. In addition, as shown in Figure 10c,d, the absorption band at $1714 \mathrm{~cm}^{-1}$ corresponds to the $\mathrm{C}=\mathrm{O}$ stretching, 2964 and $721 \mathrm{~cm}^{-1}$ are due to the stretching vibration of $-\mathrm{CH}_{2}$ bonds and the out-of-plane bending vibration on the benzene ring of polyester fibers in the control and treated $\mathrm{T} / \mathrm{V}$ and $\mathrm{T} / \mathrm{C}$ fabrics [37]. For polyester, there are no other polar groups except for the presence of two alcohol-terminated hydroxyl groups in the molecule. However, the characteristic absorption peak of $-\mathrm{OH}$ appears at $3430 \mathrm{~cm}^{-1}$ of T/C and T/V fabrics, which is due to the large amount of $-\mathrm{OH}$ contained in cotton and viscose fibers. The characteristic absorption peaks of cellulose and polyester fibers were almost unchanged before and after treatment. However, a new characteristic peak appeared at about $1560-1570 \mathrm{~cm}^{-1}$ in four kinds of knitted fabrics treated by dipping and pad-dry-cure processes attributed to the stretching vibration of $\mathrm{C}=\mathrm{C}, \mathrm{C}=\mathrm{N}$ and $\mathrm{C}-\mathrm{N}$ bonds of the six-membered ring on TLP [38]. This indicates that a nucleophilic substitution reaction occurs between $\mathrm{C}-\mathrm{Cl}$ bonds on TLP and the hydroxyl groups of the chain of cellulose macromolecules. The reaction pathways are shown in Figure 11.

\subsection{XRD Analysis}

Figure 12 shows the XRD spectra of the fabrics before and after TLP modification finishing. Compared with original fabrics, the characteristic diffraction peaks of all dipping process-treated fabrics have no obvious difference, indicating the surface treatment does not affect the original crystalline form of pristine fabric regardless of the heterogeneous modification. The crystallinity is relative to the molecular arrangement and tightness. The looser the arrangement of fibers' molecules, 
the lower the crystallinity [39]. Therefore, these treatments did not damage the main structure of cellulose and polyester, and the modification only occurred on the active surface of the cellulose fibers.
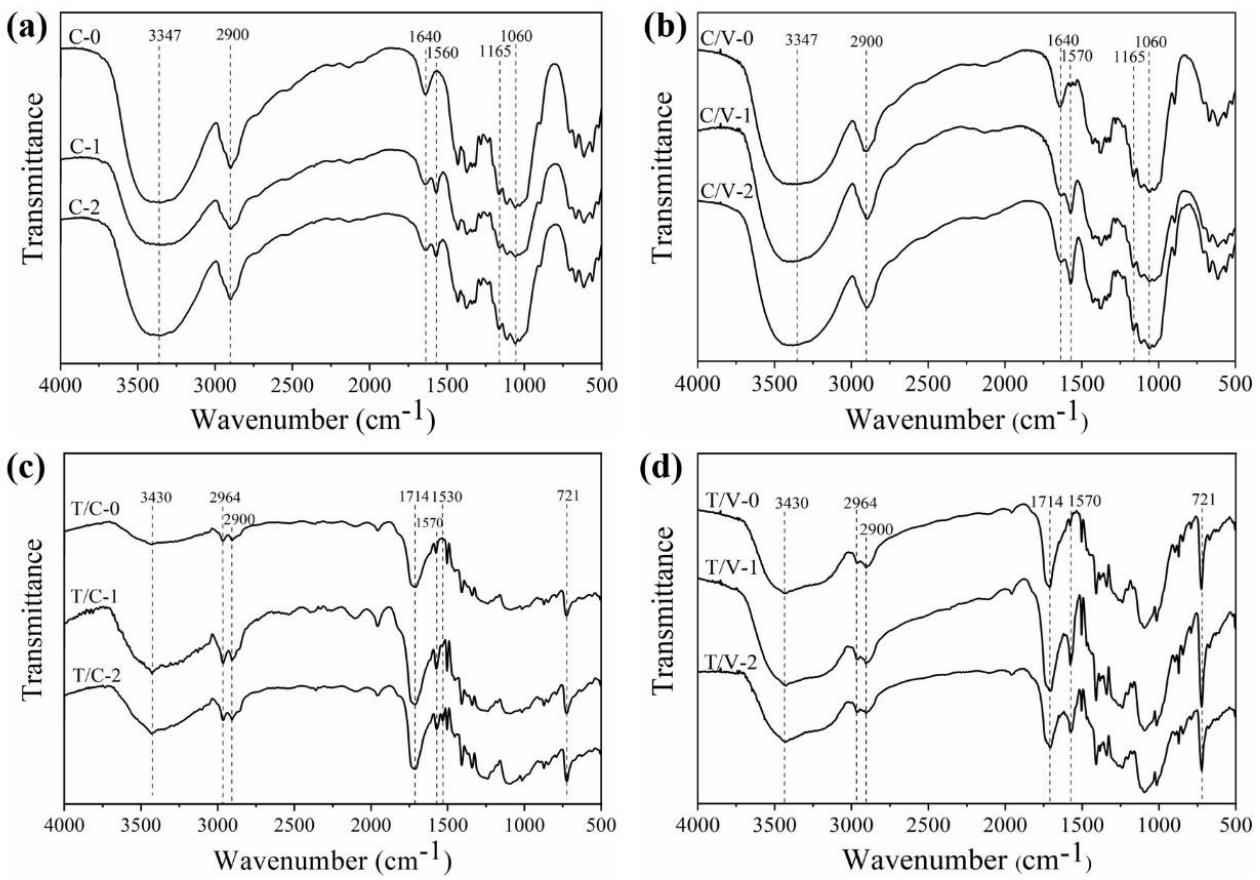

Figure 10. The FTIR spectra of original and treated fabrics with dipping and pad-dry-cure processes. (a) cotton (C); (b) cotton/viscose (C/V); (c) polyester/cotton (T/C); (d) polyester/viscose (T/V).

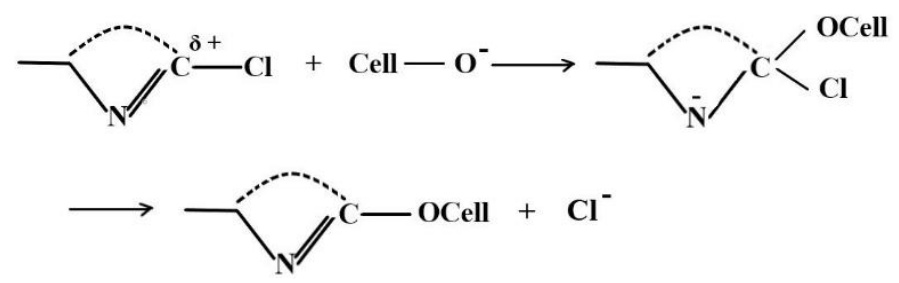

Figure 11. Schematic diagram of the reaction between cellulose and chloropyrimidine.

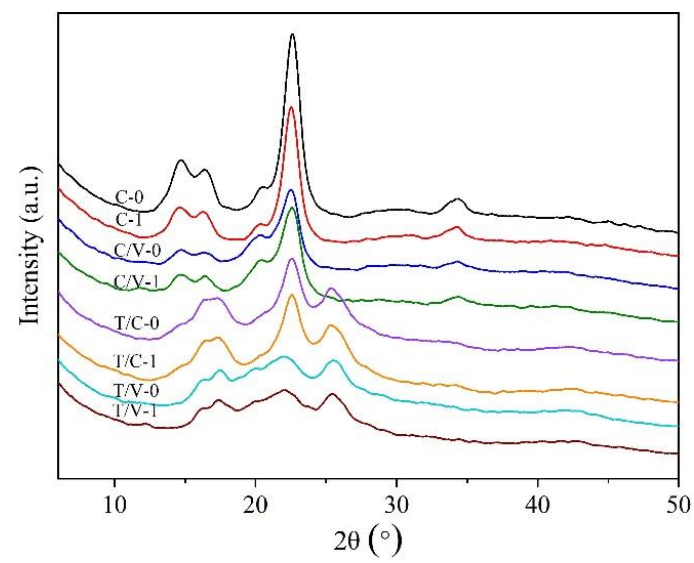

Figure 12. XRD spectra of original and dipping process-treated fabrics.

\subsection{TG and DTG Analysis}

For the original $\mathrm{C}$ and $\mathrm{C} / \mathrm{V}$, three thermal degradation stages are clearly detected in an air atmosphere (Figure 13a,b). The first stage is observed below $100^{\circ} \mathrm{C}$, giving rise to a weight loss of about 
$5.6 \%$ and $8.8 \%$, which could be attributed to the evaporation of moisture adsorbed in the fabrics [40]. The fast and most significant mass loss takes place in the second stages at $250-350{ }^{\circ} \mathrm{C}$, leading to a weight loss of about $73.1 \%$ and $63.4 \%$, corresponding to the decomposition of cellulose fabrics into small molecules. The third stage at $350-490^{\circ} \mathrm{C}$ involves the oxidative reaction of the residues. For the original $\mathrm{T} / \mathrm{C}$ and $\mathrm{T} / \mathrm{V}$, in addition to the water absorption below $100{ }^{\circ} \mathrm{C}$ and cellulose fiber decomposition in the range of $250-350{ }^{\circ} \mathrm{C}$, the highest weight loss of polyester and cellulose residue decomposition appeared at $350-450{ }^{\circ} \mathrm{C}$, and the peak temperature was $427^{\circ} \mathrm{C}$. This is due to the polyester fibers recrystallizing into a more stable form after the previous melting and melt again at a higher temperature. The reason for this rapid pyrolysis at stage II is the release of high-boiling volatiles [41]. The last stage is the decomposition of small molecular compounds above $450{ }^{\circ} \mathrm{C}$. According to the TG and DTG curves, compared with original fabrics, the introduction of TLP improved the decomposition of cellulose and decreased the $T_{\max }$ value in the second decomposition stage. It can be supposed that the 2,4,6-trichloropyrimidine compounds decompose at first, inducing the degradation of cellulose and favoring the generation of thermally stable char layer at a lower temperature.
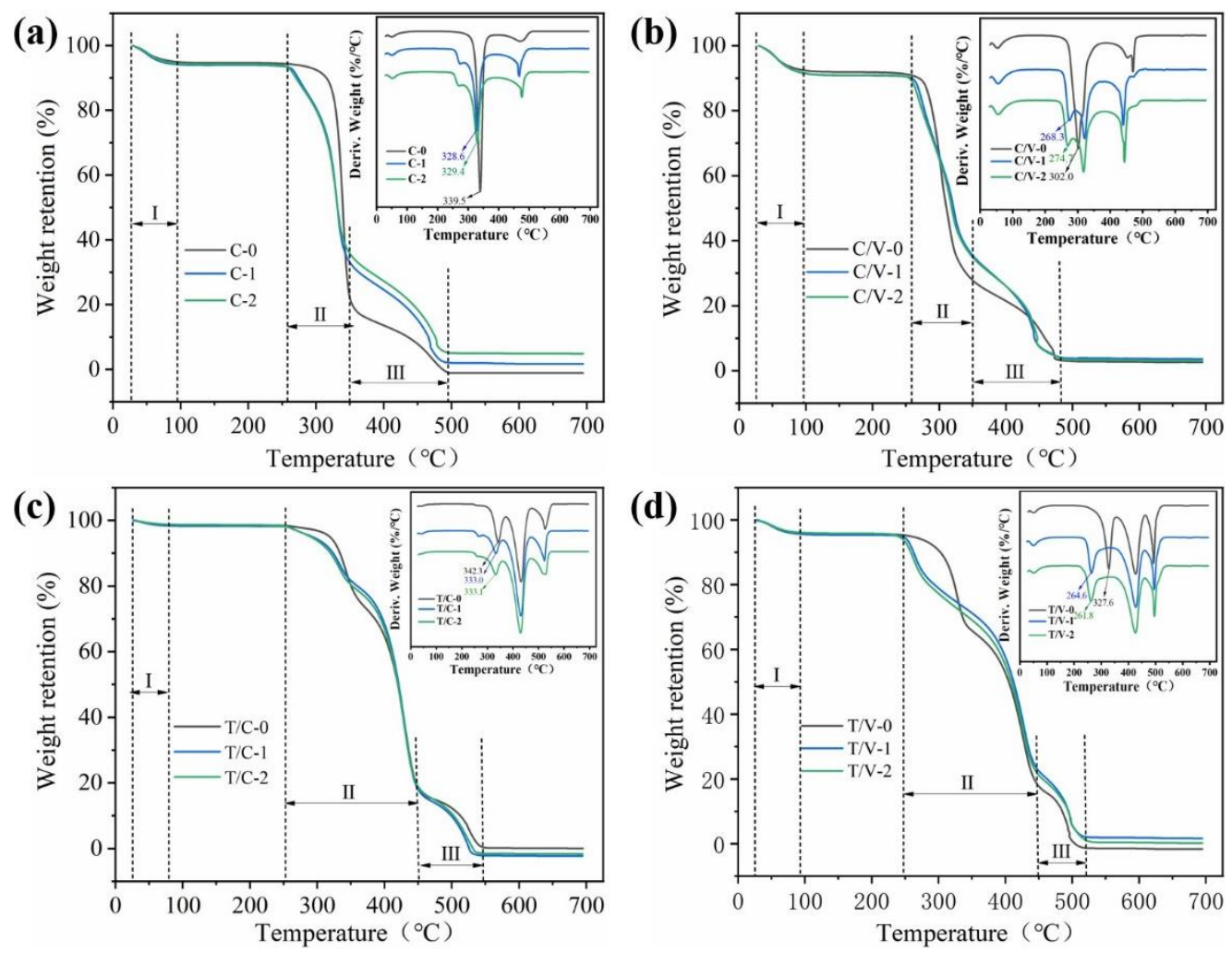

Figure 13. TG and DTG of original and treated cotton fabrics. (a) cotton; (b) cotton/viscose; (c) polyester/cotton; (d) polyester/viscose.

\subsection{Physical and Mechanical Properties}

The bursting strength, permeability, antistatic property, bending and surface friction properties of untreated and treated fabrics were evaluated. As shown in Table 3, the bursting strength of treated fabrics had decreased after dipping and pad-dry-cure processes treatment, ascribed to the long-term alkaline and high-temperature curing condition of the finishing process. However, a decrease within $18.7 \%$ can be acceptable in the wet processing of textiles [31]. The air permeability of the treated fabrics also slightly decreased due to the reduction in interweaved interspaces between fibers derived from the chloropyrimidine films formed on the surface of fibers. Besides, the antistatic property of treated fabrics improved sharply, especially for T/C and T/V blended knitted fabrics. For example, the static half period and electrostatic voltage of the untreated $\mathrm{T} / \mathrm{C}$ fabric is $3.10 \mathrm{~s}$ and $+1.00 \mathrm{kV}$, while the dipping 
process-treated sample is $0.23 \mathrm{~s}$ and $+0.66 \mathrm{kV}$. The enhancement of the antistatic property can greatly improve the wearing comfort of the polyester-containing fabrics.

Table 3. Bursting strength, permeability and antistatic property of original and treated fabrics.

\begin{tabular}{ccccc}
\hline Sample & Bursting Strength (N) & Permeability (mm/s) & Static Half Period (s) & Antistatic Property \\
Electrostatic Voltage (kV)
\end{tabular}

Table 4 shows all of the treated fabrics have an increase in $\mathrm{B}$ and $2 \mathrm{HB}$ values, which can be primarily attributed to the enhancement of inter-yarn friction and the number of fibers contacting at yarn crossover points in the treated fabrics [42]. Furthermore, an alkaline reaction medium could result in brittleness of the fabric and make the treated fabric stiffer. In addition, the MIU values of treated fabrics increased a little, which means the surface of treated fabrics is rougher than the original fabric. The increase in surface roughness can be mainly attributed to the particles and films formed on the surface of treated fibers. In general, fabrics with low B, 2HB, MIU and SMD values have better bending and surface friction properties. The bending and surface friction properties of treated fabrics had no obvious change and still maintained a soft and smooth handle.

Table 4. Bending properties and surface friction properties of original and treated fabrics.

\begin{tabular}{ccccccccc}
\hline \multirow{2}{*}{ Sample } & \multicolumn{2}{c}{$\begin{array}{c}\text { B } \\
\text { (gf cm } \mathbf{2} / \mathbf{c m})\end{array}$} & \multicolumn{2}{c}{$\begin{array}{c}\text { 2HB } \\
\text { (gf cm/cm) }\end{array}$} & \multicolumn{2}{c}{ MIU } & \multicolumn{2}{c}{$\begin{array}{c}\text { SMD } \\
(\boldsymbol{\mu m})\end{array}$} \\
\cline { 2 - 10 } & Warp & Weft & Warp & Weft & Warp & Weft & Warp & Weft \\
\hline C-0 & 0.0358 & 0.0338 & 0.0315 & 0.0435 & 0.187 & 0.206 & 2.013 & 5.387 \\
C-1 & 0.0398 & 0.0381 & 0.0329 & 0.0443 & 0.215 & 0.221 & 2.282 & 4.987 \\
C-2 & 0.0432 & 0.0419 & 0.0478 & 0.0589 & 0.204 & 0.219 & 2.318 & 5.126 \\
C/V-0 & 0.0103 & 0.0097 & 0.0109 & 0.0115 & 0.172 & 0.205 & 2.745 & 3.860 \\
C/V-1 & 0.0173 & 0.0264 & 0.0142 & 0.0359 & 0.194 & 0.222 & 2.505 & 3.486 \\
C/V-2 & 0.0137 & 0.0257 & 0.0138 & 0.0325 & 0.188 & 0.232 & 2.125 & 3.880 \\
T/C-0 & 0.0143 & 0.0099 & 0.0122 & 0.0174 & 0.184 & 0.200 & 2.233 & 4.973 \\
T/C-1 & 0.0189 & 0.0119 & 0.0288 & 0.0302 & 0.219 & 0.226 & 2.013 & 4.643 \\
T/C-2 & 0.0136 & 0.0137 & 0.0115 & 0.0149 & 0.211 & 0.243 & 2.282 & 4.418 \\
T/V-0 & 0.0076 & 0.0094 & 0.0115 & 0.0151 & 0.282 & 0.280 & 2.350 & 4.530 \\
T/V-1 & 0.0113 & 0.0099 & 0.0165 & 0.0196 & 0.314 & 0.290 & 2.160 & 4.109 \\
T/V-2 & 0.0102 & 0.0097 & 0.0132 & 0.0120 & 0.290 & 0.299 & 2.373 & 3.528 \\
\hline
\end{tabular}

\subsection{Whiteness, Color Parameters and Colorfastness}

To determine the color change between treated and original fabric samples, the whiteness of undyed samples, color parameters and color fastness of dyed samples were determined. As shown in Table 5, the high-temperature curing induced yellowness on the surface of undyed C and T/C fabrics, while the dipping process did not reduce the whiteness of fabrics, and even improved a little. In addition, the two finishing processes did not significantly change the L, a, b, C and $\mathrm{H}$ values, rubbing fastness and washing fastness of the dyed fabrics after dipping and pad-dry-cure modification treatments, indicating that the finishing processes had no significant influence on the color characteristics and fastness of the fabrics. 
Table 5. Whiteness, color parameters and colorfastness of original and treated fabrics.

\begin{tabular}{|c|c|c|c|c|c|c|c|c|c|c|}
\hline \multirow[t]{2}{*}{ Sample } & \multirow[t]{2}{*}{ Whiteness (\%) } & \multicolumn{5}{|c|}{ Color Parameter } & \multicolumn{2}{|c|}{$\begin{array}{l}\text { Rubbing } \\
\text { Fastness }\end{array}$} & \multicolumn{2}{|c|}{$\begin{array}{l}\text { Washing } \\
\text { Fastness }\end{array}$} \\
\hline & & $\mathbf{L}$ & a & b & $\mathrm{C}$ & $\mathbf{H}$ & Dry & Wet & Staining & Fastness \\
\hline $\mathrm{C}-0$ & 80.53 & 95.44 & -0.24 & 1.80 & 1.82 & 97.70 & - & - & - & - \\
\hline C-1 & 80.57 & 95.76 & -0.34 & 1.96 & 2.00 & 99.90 & - & - & - & - \\
\hline $\mathrm{C}-2$ & 68.11 & 94.30 & 0.13 & 4.01 & 4.02 & 91.80 & - & - & - & - \\
\hline $\mathrm{C} / \mathrm{V}-0$ & - & 20.95 & 1.57 & -11.16 & 11.27 & 277.99 & 4 & $3-4$ & $4-5$ & 4 \\
\hline $\mathrm{C} / \mathrm{V}-1$ & - & 21.46 & 1.17 & -11.15 & 11.21 & 275.99 & 4 & 3 & $4-5$ & 4 \\
\hline $\mathrm{C} / \mathrm{V}-2$ & - & 20.67 & 1.69 & -11.09 & 11.22 & 278.64 & 4 & 3 & $4-5$ & 4 \\
\hline $\mathrm{T} / \mathrm{C}-0$ & 78.82 & 95.52 & -0.53 & 2.22 & 2.28 & 103.42 & - & - & - & - \\
\hline $\mathrm{T} / \mathrm{C}-1$ & 79.25 & 95.56 & -0.56 & 2.15 & 2.21 & 104.47 & - & - & - & - \\
\hline $\mathrm{T} / \mathrm{C}-2$ & 68.30 & 94.80 & -0.53 & 4.14 & 4.17 & 97.35 & - & - & - & - \\
\hline $\mathrm{T} / \mathrm{V}-0$ & - & 55.66 & -0.18 & -1.05 & 1.06 & 260.39 & $4-5$ & 4 & $4-5$ & 4 \\
\hline $\mathrm{T} / \mathrm{V}-1$ & - & 55.39 & -0.12 & -1.36 & 1.36 & 265.07 & $4-5$ & 4 & $4-5$ & 4 \\
\hline $\mathrm{T} / \mathrm{V}-2$ & - & 55.81 & -0.14 & -0.82 & 0.84 & 260.28 & $4-5$ & 4 & $4-5$ & 4 \\
\hline
\end{tabular}

\section{Conclusions}

In this work, four different kinds of cellulose fiber blended knitted fabrics were treated with an alkaline 2,4,6-trichloropyrimidine emulsion system by dipping and pad-dry-cure processes to improve the anti-pilling performance. The results suggested that the finishing process provided films and particles on the surface of the fabrics and crosslinking occurred between fibers, which restricted the entanglement of the fiber ends on the surface of the fabrics and the fiber movements, thus reducing the phenomenon of fabric pilling. The treated fabrics achieved excellent and durable anti-pilling performance. Meanwhile, due to the high-temperature curing or films formed by crosslinking, the two finishing processes may cause a slight increase in bending and surface friction properties. However, there was no significant damage to the physical and mechanical properties of the treated fabrics. In addition, compared with original samples, the anti-static properties of treated fabrics were greatly improved due to the inhibition of fibrillation and scattered fuzz entangled in balls. Besides, the colorfastness of knitted dyed fabrics was good and no significant yellowness was observed on undyed samples with the dipping process treatment. The results of this study clearly demonstrate the effectiveness and potential of pyrimidine compounds in anti-pilling modification. It can be further applied to textile functional finishing and home-caring processes.

Author Contributions: Conceptualization, G.C. and X.D.; data curation, X.D.; formal analysis, X.D. and T.X.; investigation, G.C.; resources, X.D.; writing—original draft preparation, X.D.; writing-review and editing, T.X. and G.C.; funding acquisition, T.X. and G.C. All authors have read and agreed to the published version of the manuscript.

Funding: This research was funded by the National Nature Science Foundation of China $(51973144,51741301)$; the Priority Academic Program Development of Jiangsu Higher Education Institutions (PAPD).

Conflicts of Interest: The authors declare no conflict of interest.

\section{References}

1. Wan, A.; Yu, W. Effect of wool fiber modified by ecologically acceptable ozone-assisted treatment on the pilling of knit fabrics. Text Res. J. 2012, 82, 27-36. [CrossRef]

2. Dalbasi, E.S.; Ozcelik Kayseri, G. A research about the effect of the anti-pilling treatments on different structured cotton knitted fabrics. Tekstil Konfeksiyon 2015, 25, 54-60.

3. Liu, Y.; Xia, L.; Zhang, Q.; Guo, H.; Wang, A.; Xu, W.; Wang, Y. Structure and properties of carboxymethyl cotton fabric loaded by reduced graphene oxide. Carbohyd. Polym. 2019, 214, 117-123. [CrossRef] [PubMed]

4. Zhu, L.; Ding, X.M.; Wu, X.Y. A novel method for improving the anti-pilling property of knitted wool fabric with engineered water nanostructures. J. Mater. Res. Technol. 2020, 102, 3649-3658. [CrossRef]

5. Rong, L.; Liu, H.; Wang, B.; Xu, H.; Zhang, L.; Zhong, Y.; Feng, X.; Sui, X. Durable antibacterial and hydrophobic cotton fabrics utilizing enamine bonds. Carbohyd. Polym. 2019, 211, 173-180. [CrossRef] [PubMed] 
6. Xu, Y.; Chen, D.; Du, Z.; Li, J.; Wang, Y.; Yang, Z. Structure and properties of silk fibroin grafted carboxylic cotton fabric via amide covalent modification. Carbohyd. Polym. 2017, 161,99-108. [CrossRef]

7. Wan, A.; Yu, W.; Jiang, G. Pilling properties of wool single jersey made of compact and conventional ring yarns after anti-felting treatment. Text Res. J. 2014, 84, 673-680. [CrossRef]

8. Karahan, H.A.; Ozdoggan, E.; Demir, A. Effects of atmospheric pressure plasma treatments on some physical properties of wool fibers. Text Res. J. 2009, 79, 1260-1265. [CrossRef]

9. Huang, Z.; Chen, W. Preparation and characterization of Hot Melt Copolyster (PBTI) ultrafine particles and their effect on the anti-pilling performance of polyester/cotton fabrics. Polymers 2018, 10, 1163. [CrossRef] [PubMed]

10. Shavandi, A.; Ali, M.A. Graft polymerization onto wool fiber for improved functionality. Prog. Org. Coat. 2019, 130, 182-199. [CrossRef]

11. Wan, A.; Dai, X.J.; Magniez, K.; Plessis, J.; Yu, W.D.; Wang, X.G. Reducing the pilling propensity of wool knits with a three-step plasma treatment. Text Res. J. 2013, 83, 2051-2059. [CrossRef]

12. Khandual, A.; Luximon, A.; Pattanayak, A.K. Optimization of acid cellulose enzyme concentration to reduce pilling of bamboo fabric: An objective assessment approach. Fiber Polym. 2011, 12, 816-820. [CrossRef]

13. Kowalczyk, D.; Brzeziński, S.; Kamińska, I. Multifunctional bioactive and improving the performance durability nano coatings for finishing PET/CO woven fabrics by the sol-gel method. J. Alloys Compd. 2015, 649, 387-393. [CrossRef]

14. Kim, S.; Park, C.K. Evaluation of fabric pilling using hybrid imaging methods. Fiber Polym. 2006, 7, 57. [CrossRef]

15. Rombaldoni, F.; Mossotti, R.; Montarsolo, A.; Songia, M.B.; Innocenti, R.; Mazzuchetti, G. Thin film deposition by PECVD using HMDSO- $\mathrm{O}_{2}$-Ar gas mixture on knitted wool fabrics in order to improve pilling resistance. Fiber Polym. 2008, 9, 566-573. [CrossRef]

16. Yang, S.; Zhang, C.; Shen, X. Reducing pilling of knitted woolen fabric based on micro-scale. Int. J. Cloth. Sci. Technol. 2017, 29, 138-147.

17. Periolatto, M.; Ferrero, F.; Vineis, C.; Rombaldoni, F. Multifunctional finishing of wool fabrics by chitosan UV-grafting: An approach. Carbohyd. Polym. 2013, 98, 624-629. [CrossRef]

18. Schroeder, M.; Schweitzer, H.B.M.; Guebitz, G.M. Chemical modification of proteases for wool cuticle scale removal. Biocatal. Biotransform. 2004, 22, 299-305. [CrossRef]

19. Montazer, M.; Mazaheri, F.; Khosravian, S.; Azimi, M.; Bameni Moghadam, M.; Sadeghi, A.H. Application of resins and crosslinking agents on fiber blend fabric to reduce pilling performance, optimized by response surface methodology. J. Vinyl Addit. Technol. 2011, 17, 213-221. [CrossRef]

20. Milind, M.; Pant, S. Effect of resin finishes on pilling and dimensional stability of knitted fabrics. Man Made Text. India 2014, 42, 9-12.

21. $\mathrm{Xu}, \mathrm{W}$.; Zhou, $\mathrm{X}$. Synthesis and application of silicone modified polyurethane anti-pilling finishing agent. Text. Aux. 2018, 35, 18-21.

22. Textor, T.; Knittel, D.; Bahners, T.; Schollmeyer, E. Inorganic-organic hybrid polymers for coating textile materials. Curr. Trends Polym. Sci. 2003, 8, 127-133.

23. Noreen, H.; Zia, M.A.; Ali, S.; Hussain, T. Optimization of bio-polishing of polyester/cotton blended fabrics with cellulases prepared from Aspergillus niger. Indian J. Biot. 2014, 13, 108-113.

24. Kan, C.W.; Yuen, C.W.M. Effect of low temperature plasma treatment on wool fabric properties. Fiber Polym. 2005, 6, 169-173. [CrossRef]

25. Mossotti, R.; Lopardo, G.; Innocenti, R. Characterization of plasma-coated wool fabrics. Text. Res. 2009, 79, 853-861. [CrossRef]

26. Millington, K. Using ultraviolet radiation to reduce pilling of knitted wool and cotton. Text. Res. 1998, 68, 413-421. [CrossRef]

27. El-Sayed, H.; El-Khatib, E. Modification of wool fabric using ecologically acceptable UV-assisted treatments. J. Chem. Technol. Biot. 2010, 80, 1111-1127. [CrossRef]

28. Mei, N.; Liu, X.; Dai, J.; Hou, W.; Xu, B. UV-induced grafting of organic-inorganic antibacterial membrane on wool fiber. Prog. Org. Coat. 2012, 74, 622-628.

29. Sun, F.F.; Ma, N.; Li, Z.M. 2-Amino-4-(2,2,2-trifluoroethoxy) pyrimidine. Acta Cryst. 2006, 62, $3864-3865$. [CrossRef] 
30. Zuber, M.; Zia, K.M.; Tabassum, S.; Jamil, T.; Barkaat-ul-Hasin, S.; Khosa, M.K. Preparation of rich handles soft cellulosic fabric using amino silicone based softener, part II: Color fastness properties. Int. J. Biol. Macromol. 2011, 49, 1-6. [CrossRef]

31. Cheng, X.W.; Tang, R.C.; Guan, J.P.; Zhou, S.Q. An eco-friendly and effective flame retardant coating for cotton fabric based on phytic acid doped silica sol approach. Prog. Org. Coat. 2020, 141, 105539-105547. [CrossRef]

32. Zahid, M.; Heredia-Guerrero, J.A.; Athanassiou, A.; Bayer, I.S. Robust water repellent treatment for woven cotton fabrics with eco-friendly polymers. Chem. Eng. J. 2017, 319, 321-332. [CrossRef]

33. Hearle, J.W.S.; Wilkins, A.H. Movement of fibers in assemblies. Text. Inst. 2006, 97, 1-9. [CrossRef]

34. Garside, P.; Wyeth, P. Identification of cellulosic fibers by FTIR spectroscopy-thread and single fiber analysis by attenuated total reflectance. Stud. Conserv. 2003, 48, 269-275. [CrossRef]

35. Chung, C.; Lee, M.; Choe, E.K. Characterization of cotton fabric scouring by FT-IR ATR spectroscopy. Carbohydr. Polym. 2004, 58, 417-420.

36. Bran, J.; Pecastaings, G.; Sèbe, G. A versatile method for the surface tailoring of cellulose nanocrystal building blocks by acylation with functional vinyl esters. Carbohyd. Polym. 2017, 169, 189-197. [CrossRef] [PubMed]

37. Mihiri Ekanayake, U.G.; Dissanayake, D.M.S.N.; Rathuwadu, N.; Kumarasinghe, R.K.K.G.R.G.; Sanjeewa, K.R.; Mantilaka, M.M.M.G.P.G. Facile fabrication of fiuoro-polymer self-assembled ZnO nanoparticles mediated, durable and robust omniphobic surfaces on polyester fabrics. J. Fluor. Chem. 2020, 235, 109565. [CrossRef]

38. Xu, Y.H.; Liu, X.; Liu, X.L.; Tan, J.L.; Zhu, H.L. Influence of $\mathrm{HNO}_{3} / \mathrm{H}_{3} \mathrm{PO}_{4}-\mathrm{NaNO}_{2}$ mediated oxidation on the structure and properties of cellulose fibers. Carbohyd. Polym. 2014, 111, 955-963. [CrossRef] [PubMed]

39. Dong, W.W.; Zhou, M.; Li, Y.; Zhai, S.X.; Jin, K.L.; Fan, Z.Z.; Zhao, H.; Zou, W.R.; Cai, Z.S. Low-salt dyeing of cotton fabric grafted with $\mathrm{pH}$-responsive cationic polymer of polyelectrolyte 2-(N,N-dimethylamino) ethyl methacrylate. Colloids Surf. A 2020, 594, 124573. [CrossRef]

40. López, F.A.; Mercê, A.L.R.; Alguacil, F.J.; López-Delgado, A. A kinetic study on the thermal behaviour of chitosan. J. Therm. Anal. Calorim. 2008, 91, 633-639. [CrossRef]

41. Liu, W.; Wang, N.; Han, J.W.; Xu, J.Q.; Li, Z.H.; Qin, W.Q. Thermal degradation behaviors and evolved products analysis of polyester paint and waste enameled wires during pyrolysis. Waste Manag. 2020, 107, 82-90. [CrossRef] [PubMed]

42. Kan, C.W.; Lam, Y.L. Low stress mechanical properties of plasma-treated cotton fabric subjected to zinc oxide-anti-microbial treatment. Materials 2013, 6, 314-333. [CrossRef] [PubMed] 